NASA Technical Memorandum 106650

\title{
Atomic Oxygen Treatment for Non-Contact Removal of Organic Protective Coatings From Painting Surfaces
}

Sharon K. Rutledge and Bruce A. Banks

Lewis Research Center

Cleveland, Ohio

Michael Cales

Cleveland State University

Cleveland, Ohio

Prepared for the

Materials Issues in Art and Archaeology IV

sponsored by the Materials Research Society

Cancun, Q.R. Mexico, May 16-20, 1994

National Aeronautics and

Space Administration 


\title{
ATOMIC OXYGEN TREATMENT FOR NON-CONTACT REMOVAL OF ORGANIC PROTECTIVE COATINGS FROM PAINTING SURFACES
}

\author{
SHARON K. RUTLEDGE*, BRUCE A. BANKS*, AND MICHAEL CALES** \\ "NASA Lewis Research Center, 21000 Brookpark Rd. Cleveland, OH 44135 \\ ** Cleveland State University c/o NASA LeRC 21000 Brookpark Rd. Cleveland, OH 44135
}

\begin{abstract}
Current techniques for removal of varnish (lacquer) and other organic protective coatings from paintings involve contact with the surface. This contact can remove pigment, or alter the shape and location of paint on the canvas surface. A thermal energy atomic oxygen plasma, developed to simulate the space environment in low Earth orbit, easily removes these organic materials. Uniform removal of organic protective coatings from the surfaces of paintings is accomplished through chemical reaction. Atomic oxygen will not react with oxides so that most paint pigments will not be affected by the reaction. For paintings containing organic pigments, the exposure can be carefully timed so that the removal stops just short of the pigment. Color samples of Alizarin Crimson, Sap Green, and Zinc White coated with Damar lacquer were exposed to atomic oxygen. The lacquer was easily removed from all of the samples. Additionally, no noticeable change in appearance was observed after the lacquer was reapplied. The same observations were made on a painted canvas test sample obtained from the Cleveland Museum of Art. Scanning electron microscope photographs showed a slight microscopic texturing of the vehicle after exposure. However, there was no removal or disturbance of the paint pigment on the surface. It appears that noncontact cleaning using atomic oxygen may provide a viable alternative to other cleaning techniques. It is especially attractive in cases where the organic protective surface cannot be acceptably or safely removed by conventional techniques.
\end{abstract}

\section{INTRODUCTION}

Varnishes are considered to be the most vulnerable portions of oil and tempera paintings which date to before the mid-nineteenth century ${ }^{1}$. As the varnish ages, it tends to yellow and crack which affects the general appearance of the painting. Restoration typically involves removal of the varnish with the use of organic solvents ${ }^{1}$. These solvents, however, may cause swelling or leaching of the paint layers ${ }^{2}$. Immersion and/or swabbing during solvent cleaning may also cause pigment movement or removal through mechanical contact. In addition, some varnishes such as polyurethane cannot be safely removed using a solvent ${ }^{3}$. Therefore, there is a need for a noncontact varnish removal technique which can remove many different types of organic varnishes. Atomic oxygen has been shown to chemically react with organic coatings such as polyurethane, acrylic, and other lacquers. In the reaction, the coating is converted to mostly carbon monoxide and water vapor which are pumped away by the vacuum system ${ }^{4}$. Many facilities currently exist for producing atomic oxygen. They usually expose samples to a beam of atoms at very low energies or surround the surface with a plasma ${ }^{5}$. The exposure is typically performed in a vacuum chamber with pressures ranging from 100 to $10^{-3}$ millitorr depending on the technique used. It is a dry process, so there is no risk of leaching or swelling. In addition, the atomic oxygen reaction is confined to the surface with little effect on the paint or underlying canvas. This paper explores the use of atomic oxygen for organic protective coating removal. 
Measurements of the lacquer loss and changes in the appearance or gloss (reflectance) of the painting were used to determine the effectiveness of the technique.

\section{PROCEDURE}

\section{Color Samples}

Three paint colors (Alizarin Crimson (Winsor \& Newton \#1, Linseed Oil vehicle with 1:2 Dihydroxyanthraquinone Lake pigment), Sap Green (Winsor \& Newton \#37, Linseed Oil vehicle with Ferrous beta naphthol complex - Tartrazine lake pigment), and Zinc White (Winsor \& Newton \#45, Safflower Oil vehicle with Zinc Oxide pigment)) were selected for application to the test coupons. This selection was based on their sensitivity to fading during conventional cleaning and the potential for color change during atomic oxygen cleaning. The paints were applied to thin $2.2 \mathrm{~cm}$ square glass slides using a soft artist's brush. A single color was applied to each slide for optical and mass change analysis. The painted slides were allowed to dry and age in a furnace kept at $37^{\circ} \mathrm{C}$ for approximately fifteen days. Damar Varnish (Grumbacher) was then applied over the samples in two thin coats using an artist's brush. The lacquer was allowed to dry between applications. Lacquer coated paint samples were returned to the furnace for further drying until the surface no longer felt tacky to the touch. Some atomic oxygen cleaned paint coupons were recoated with lacquer and allowed to dry in the same manner for comparison testing.

\section{Painting Samples}

A sample test painting of unknown origin was generously supplied by the Cleveland Museum of Art. The painting had been half coated with acrylic varnish and one quarter coated with Damar varnish. The remaining portion of the painting had been previously cleaned down to the painted surface. For exposure and analysis, the painting was cut with a band saw to $2.54 \mathrm{~cm}$ square coupons so that several could be exposed in the test chamber at the same time. Paint composition on the surface was unknown.

\section{Exposure Testing}

Exposure of the painted coupons was performed in a commercial radio frequency plasma chamber (SPI Plasma Prep II). The chamber size was approximately $10.5 \mathrm{~cm}$ in diameter by 15 $\mathrm{cm}$ long. This facility was operated using air as the plasma source gas. Inside the pyrex vacuum chamber, the samples were surrounded by a mixture of oxygen and nitrogen atoms, ions, and molecules. The oxygen atoms and ions in the thermal energy plasma chemically react with the surface and remove any organic present. The pressure in the chamber during exposure was approximately 100 millitorr. The masonite backing of the painting sample coupons was protected from the plasma by a glass backing plate. The color samples were already on glass slides and needed no further protection. 


\section{Analysis}

A Perkin-Elmer Lambda-9 UV-VIS-NIR Spectrophotometer was used to observe the change in gloss (reflectance) of the color sample surfaces. Reflectance was measured as a function of wavelength from the ultraviolet to the near infrared. Measurements were made after painting, lacquer application, atomic oxygen cleaning, and reapplication of the lacquer following atomic oxygen cleaning.

Mass of the color samples was measured before and at intervals during exposure using a Sartorius balance. These measurements were made to detect a change in the rate of mass loss. This information may provide an insight into types of techniques that may be used for monitoring of lacquer loss and end point determination.

All unexposed and exposed samples were visually examined using a Cambridge 200 scanning electron microscope (SEM) and a JOEL 840 SEM. A thin film coating of gold was applied to the surface to prevent charging of the surface during viewing. Photos were examined for changes in surface appearance and for detachment of the paint pigment from the surface.

\section{RESULTS AND DISCUSSION}

Figure 1 contains the results of the mass change observed for lacquer coated color samples exposed to atomic oxygen. The data shows that there is a slowing of the mass loss rate once the lacquer has been removed. This slowing is more readily observed for the inorganic zinc oxide

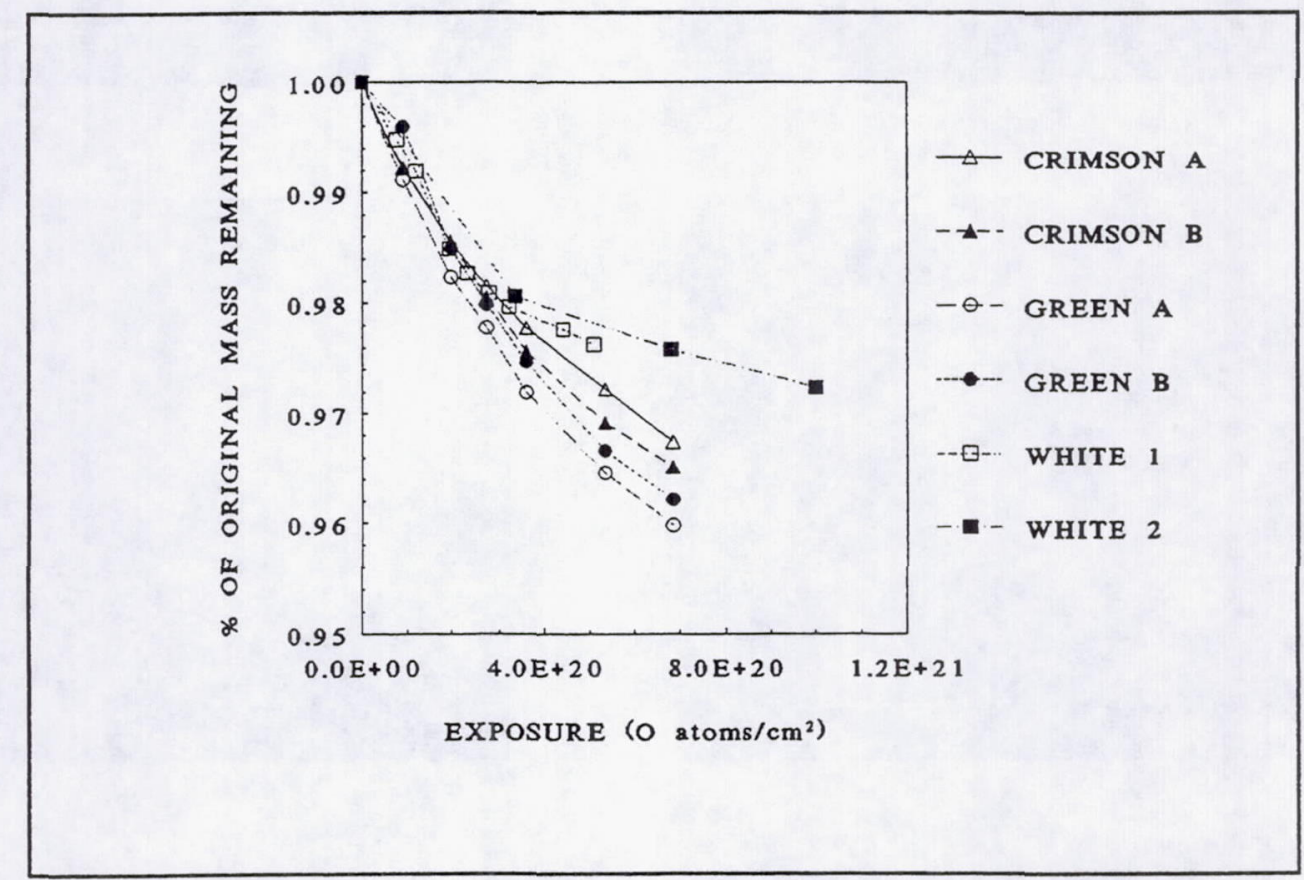

Figure 1. Percentage of mass remaining for Damar lacquer coated color samples exposed in an atomic oxygen plasma as a function of exposure duration. 
paint (white) than for the organic paints (red and green). This is expected because the zinc oxide will not react with atomic oxygen and will act as a shielding layer to the vehicle underneath.

Scanning electron photomicrographs of the surfaces revealed no apparent additional cracking or shrinking of the surface during cleaning. It was important to establish that damage does not occur due to vaporization of some of the volatile components of the paint which occurs during vacuum exposure. Figures $2 \mathrm{a}-2 \mathrm{~d}$ contain SEM image comparisons of a painting sample with no lacquer (unexposed), with Damar lacquer, and with Damar lacquer plus exposure in the atomic oxygen plasma. The atomic oxygen cleaned sample shows a fine texturing of the vehicle, but the paint pigment and particles present in the original remain on the surface. Low magnification SEM photos of the cleaned and original surfaces overall look very similar. The color samples, and the acrylic coated painting coupons also had the same appearance. On all of the samples tested, the brush strokes, canvas and pigment particles were undisturbed by the atomic oxygen cleaning.

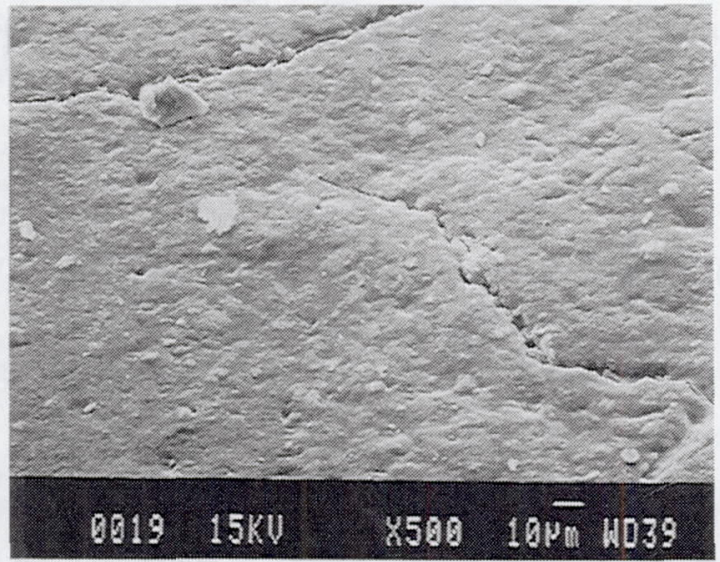

a.

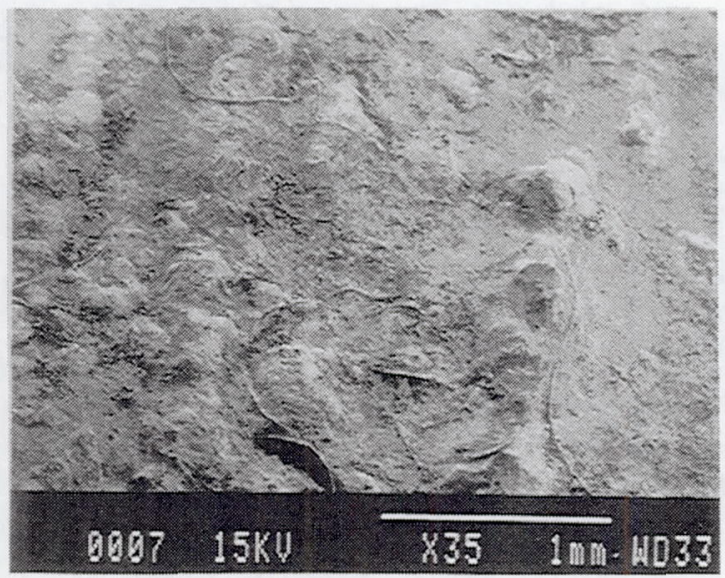

c.

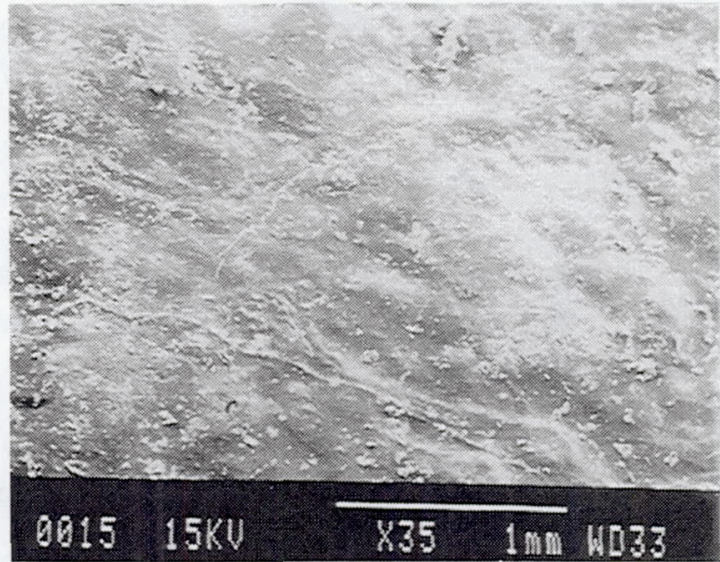

b.

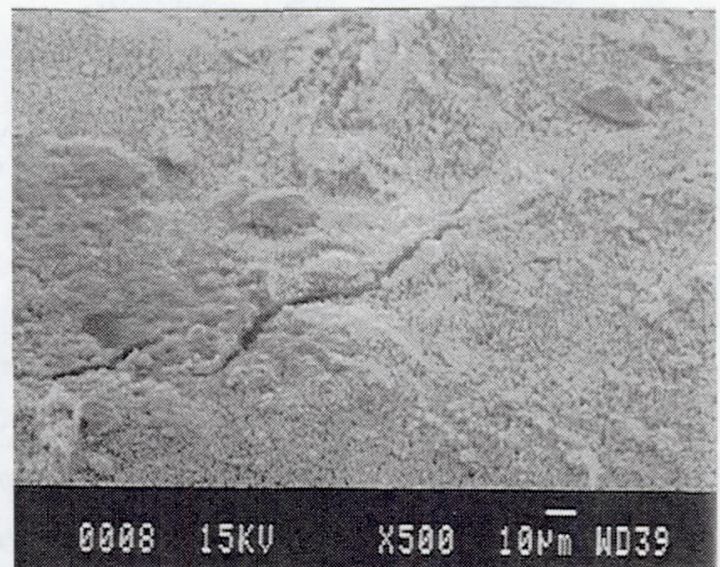

d.

Figure 2. SEM photos of painting coupons a). with no lacquer; b). with Damar lacquer; c). with Damar lacquer exposed to an atomic oxygen plasma of $4.06 \times 10^{20}$ atoms $/ \mathrm{cm}^{2}$; and d). a magnified view of c. 
Reflectance data from each of the color samples shows that there is a slight increase in reflectance of the surface upon lacquer application. Reflectance data is contained in Figures 3-4. After cleaning with atomic oxygen, the total reflectance increases due to increased diffuse light scattering from the exposed pigment particles. The surface visually appears more matte. After lacquer reapplication, the reflectance again recovers to very close to its original value. Visually the samples appear the same as the lacquered sample before cleaning. This is encouraging for cleaning of painting surfaces which are to be relacquered. If the painting is not to be relacquered, an alternate technique should be used. Surface texturing after atomic oxygen cleaning makes the

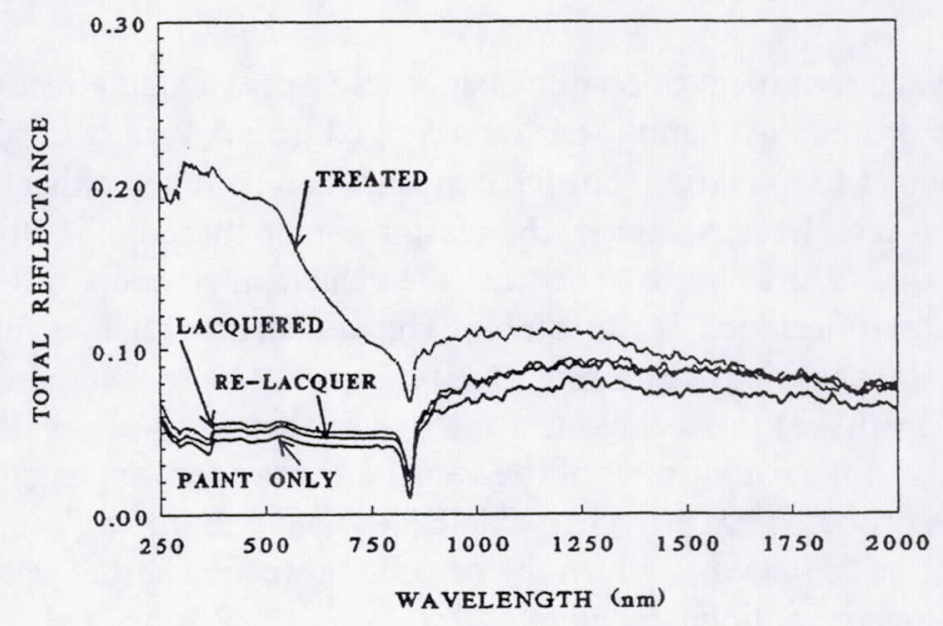

Figure 3. Reflectance of Sap Green color sample at various stages during cleaning and restoration.

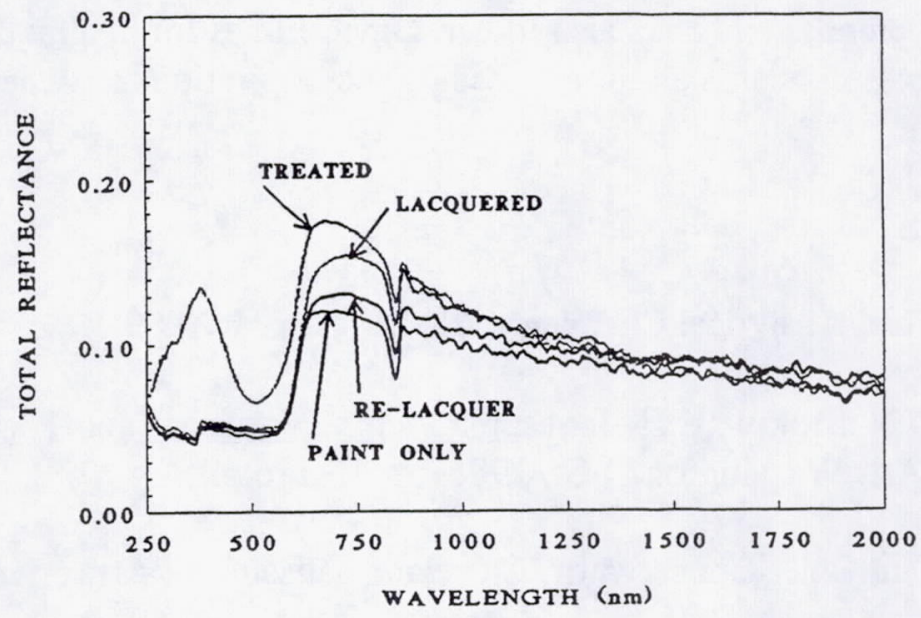

Figure 4. Reflectance of Alizarin Crimson color sample at various stages during cleaning and restoration 
colors appear faded because of the increased diffuse reflectance. Reapplication of lacquer fills in where the binder was removed and restores the surface to its original appearance.

Atomic oxygen cleaning is a process which can be scaled to fit the size of most paintings. Multiple plasma sources or rastering of the painting under a single plasma source can be used to accommodate large works of art. The main limitation on the process is the size of the vacuum chamber which must be at least as large as the painting to be treated.

\section{CONCLUSIONS}

Atomic oxygen treatment of paintings appears to provide an effective removal technique. All types of organic protective coatings can be removed from a variety of paint types. Organic pigments are subject to oxidation, but the exposure can be timed either visually or by changes in the mass removal rate. In this manner, the plasma can be turned off before too much of the pigment is removed. SEM photos show that the vehicle microscopically roughens during exposure which changes the reflectance of the sample. This reflectance change appears as a dulling of the surface due to increased light scattering. Reflectance can be recovered upon application of a fresh lacquer layer. This makes the technique attractive for paintings which need to be cleaned and relacquered. Other than roughening of the vehicle, the process appears not to damage the painting in any way. This process may provide a viable alternative to other cleaning techniques. It is especially attractive for cases in which the organic protective surface cannot be acceptably or safely removed by conventional techniques.

\section{ACKNOWLEDGEMENTS}

The principal author would like to thank Dr. Bruce Christman, Chief Conservator at the Cleveland Museum of Art, for many helpful restoration and paint sensitivity discussions, and for providing a test painting. Thanks also to Mr. David Elmes for helpful discussions about potential restoration process concerns and for providing the inspiration to try new things.

\section{REFERENCES}

1. E.R. de la Rie, Analytical Chemistry, 61, 21 (Nov. 1, 1989).

2. R.L. Feller, N. Stolow, E.H. Jones, On Picture Varnishes and Their Solvents, National Gallery of Art: Washington D.C., 1985, pp 47-116.

3. B. Christman, Chief Conservator, Cleveland Museum of Art (private communication).

4. B. Banks, et al. NASA/SDIO Space Environmental Effects on Materials Workshop, 1988, NASA Conference Publication 3035, pp 197-239.

5. B. Banks, et al. Proceeding of the 18th Annual Symposium on Applied Vacuum Science and Technology, 1989, NASA TM-101971. 
Davis Highway, Suite 1204, Arlington, VA 22202-4302, and to the Office of Management and Budget, Paperwork Reduction Project (0704-0188), Washington, DC 20503.

\begin{tabular}{|l|l|l|}
\hline 1. AGENCY USE ONLY (Leave blank) & $\begin{array}{r}\text { 2. REPORT DATE } \\
\text { July } 1994\end{array}$ & $\begin{array}{r}\text { 3. REPORT TYPE AND DATES COVERED } \\
\text { Technical Memorandum }\end{array}$ \\
\hline
\end{tabular}

4. TITLE AND SUBTITLE

5. FUNDING NUMBERS

Atomic Oxygen Treatment for Non-Contact Removal of Organic Protective

Coatings From Painting Surfaces

6. AUTHOR(S)

WU-233-01-0E

Sharon K. Rutledge, Bruce A. Banks, and Michael Cales

7. PERFORMING ORGANIZATION NAME(S) AND ADDRESS(ES)

National Aeronautics and Space Administration

Lewis Research Center

Cleveland, Ohio 44135-3191

8. PERFORMING ORGANIZATION REPORT NUMBER

E-8958

9. SPONSORING/MONITORING AGENCY NAME(S) AND ADDRESS(ES)

10. SPONSORING/MONITORING

AGENCY REPORT NUMBER

National Aeronautics and Space Administration

Washington, D.C. 20546-0001

NASA TM-106650

11. SUPPLEMENTARY NOTES

Prepared for the Materials Issues in Art and Archaeology IV sponsored by the Materials Research Society, Cancun, Q. R. Mexico, May 16-20, 1994. Sharon K. Rutledge and Bruce A. Banks, NASA Lewis Research Center; Michael Cales, Cleveland State University, Cleveland, Ohio 44115 (work funded by NASA Cooperative Agreement NCC3-19). Responsible person, Sharon K. Rutledge, organization code 5480, (216) $433-2219$.

12a. DISTRIBUTION/AVAILABILITY STATEMENT

12b. DISTRIBUTION CODE

Unclassified - Unlimited

Subject Category 27

\section{ABSTRACT (Maximum 200 words)}

Current techniques for removal of varnish (lacquer) and other organic protective coatings from paintings involve contact with the surface. This contact can remove pigment, or alter the shape and location of paint on the canvas surface. A thermal energy atomic oxygen plasma, developed to simulate the space environment in low Earth orbit, easily removes these organic materials. Uniform removal of organic protective coatings from the surfaces of paintings is accomplished through chemical reaction. Atomic oxygen will not react with oxides so that most paint pigments will not be affected by the reaction. For paintings containing organic pigments, the exposure can be carefully timed so that the removal stops just short of the pigment. Color samples of Alizarin Crimson, Sap Green, and Zinc White coated with Damar lacquer were exposed to atomic oxygen. The lacquer was easily removed from all of the samples. Additionally, no noticeable change in appearance was observed after the lacquer was reapplied. The same observations were made on a painted canvas test sample obtained from the Cleveland Museum of Art. Scanning electron microscope photographs showed a slight microscopic texturing of the vehicle after exposure. However, there was no removal or disturbance of the paint pigment on the surface. It appears that noncontact cleaning using atomic oxygen may provide a viable alternative to other cleaning techniques. It is especially attractive in cases where the organic protective surface cannot be acceptably or safely removed by conventional techniques.

\section{SUBJECT TERMS}

Restoration; Conservation; Varnish removal; Lacquer removal; Atomic oxygen

15. NUMBER OF PAGES
8

16. PRICE CODE

$\mathrm{A} 02$

17. SECURITY CLASSIFICATION OF REPORT

Unclassified

18. SECURITY CLASSIFICATION OF THIS PAGE

Unclassified
19. SECURITY CLASSIFICATION OF ABSTRACT

Unclassified 